\title{
DISTANT INFRARED SPECTRAL ANALYSIS OF INDUSTRIAL HOT GAS EJECTION IN ATMOSPHERE
}

R.S. Asatryan*1, N.R. Khachatryan ${ }^{2}$, H.S.Karayan ${ }^{3}$

*1, 2, 3 Department of theoretical metrology, National institute of Metrology, ARMENIA

\begin{abstract}
:
Passive Infrared (IR) Spectral-radiometry of gases in the atmosphere is extremely important today, when pollution of the environment by natural ejections and those produced by human activity is growing very high. Particularly, spectral analysis of hot gas ejections i.e. combustion products from industrial plants is an essential part of ecological monitoring of the atmosphere. In this paper we present the results of IR spectral analysis of hot gas ejections from industrial plants in the spectral range from 2.5 to $5.5 \mu \mathrm{m}$, at a distance of $3000 \mathrm{~m}$. The obtained with a hydrocarbon gas group, $\mathrm{SO} 2, \mathrm{~N} 2 \mathrm{O}, \mathrm{CO}$ and $\mathrm{CO} 2$ gases, as well as $\mathrm{H} 2 \mathrm{O}$ vapor. Relative content of ejected gases (to $\mathrm{CO}-\mathrm{CO} 2$ group) per unit time was evaluated by means of an integral intensity ratio for each gas. Distant IR Spectral analysis of hot gas ejections (both industrial firms, and various vehicles) have huge value, in particular at ecological monitoring of an environment.
\end{abstract}

Keywords:

Infrared spectral analysis; hot gas ejection in atmosphere; environment gas pollution.

Cite This Article: R.S. Asatryan, N.R. Khachatryan, and H.S.Karayan, "DISTANT INFRARED SPECTRAL ANALYSIS OF INDUSTRIAL HOT GAS EJECTION IN ATMOSPHERE" International Journal of Research - Granthaalayah, Vol. 3, No. 7(2015): 86-90.

\section{INTRODUCTION}

The study of gaseous components in the atmosphere plays a significant role in the sphere of ecological researches. One of main tasks of environmental control is the spectral study of chemical composition of atmosphere pollution, as well as analysis of gaseous outbursts of either industrial processes or ground transport. Important value has also distant measurements of radiation temperatures of point and extended sources of thermal radiation in an industry and in atmosphere. Therefore, the increasing applications IR Spectral Radiometry in many areas of researches have made necessary development and manufactures simples in operation, operating in application, cheap and sending IR Spectral Radiometer. Just such Spectral Radiometer was developed by our group, to which description and some researches results presentation is devoted this paper. Passive IR Spectrometry of gases in the atmosphere is extremely important today, environment by human activity is growing very high. Particularly, spectral analysis of hot-gas ejections in an essential part of ecological monitoring of the atmosphere. No less significant role has the knowledge of atmospheric IR spectral transparency, which is giving information on "Optical weather" conditions during field tests of thermal-vision equipment and other apparatus, as well as for the study of atmospheric water vapor and carbonic gas content. 


\section{INTERNATIONAL JOURNAL OF RESEARCH -GRANTHAALAYAH

\section{RESEARCH METHODS}

Developed by us "Sipan-A" IR Radiometric System is functioned in two regime-in active and passive. In active regime it works as an IR Radiometer for measuring of the local gas concentrations in surroundding space, by means of measurements of integral absorption in chosen IR band (in wavelength region from 3 to $13 \mu \mathrm{m}$ ), and in passive regime it is functioned as a distant spectral analyzer of hot gas ejections in the atmosphere. The changing Spectral Radiometer's regime work carried out by substitution of the knots photo-sensors and Light filter, and including of the external Absolute Black Body Model.

The passive regime IR Radiometer named as "USR-A" is detailed described in the work [1], there are analyzed principle of work and construction of the instrument. Structurally instrumentation "Sipan-A" consists three main units: Optic-Mechanical Unit (OMU), Electronic Control Unit (ECU) with the part of an automatized processing of the measurement results (on the personal computer), and knot of the external Absolute Black Body Model. The electrical link between them implements by means of cables. The optical scheme of the OMU is shown in a Fig. 1.

The full working spectral range of the instrument (in passive regime of works) is covered with the help of two packages of changeable light filters and photo-sensors in sub- diapasons from 2.5 to $5.5 \mu \mathrm{m}$, and $7.9-13.5 \mu \mathrm{m}$. The working spectral range of the "Sipan-A" Radiometer (in active regime of works) is covered with the help the set narrow-band interference light filters in wavelength range from 3 to $\mathrm{I} 2 \mu \mathrm{m}$. During exploitation OMU by means of cline directing placed on the rotary mechanism, which fastens to a horizontal platform specially made tripod.

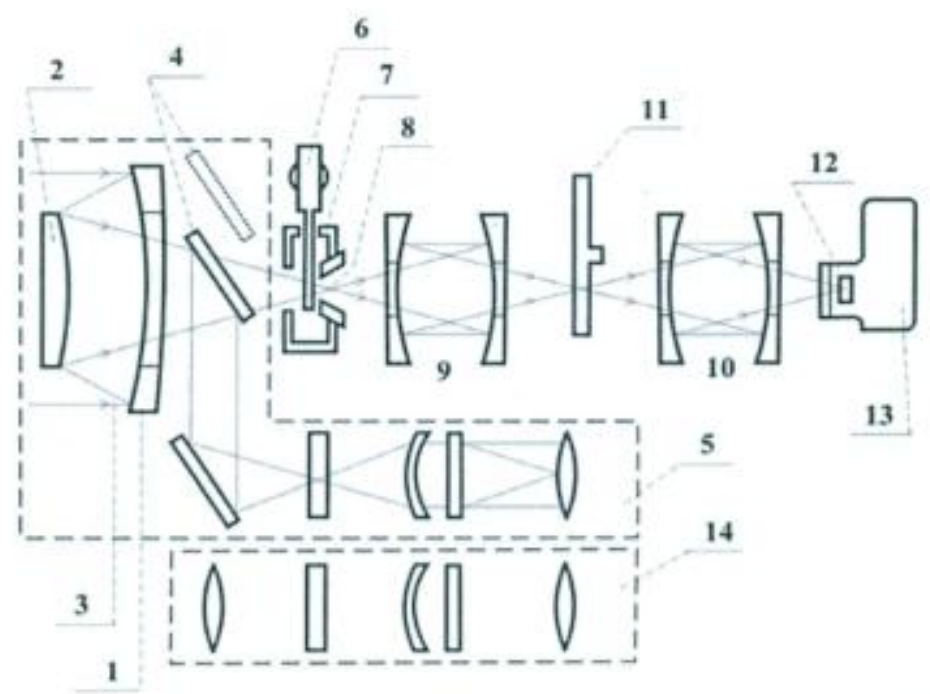

Figure 1: Optical scheme of OMU. 1-Primary mirror; 2-secondary mirror ; 3-radiation from the object; 4- removable flat mirror; 5-viser; 6-modulator; 7-basic cavity; 8- field diaphragm; 9,10projecting objective; 11- disc with interference photo filters; 12- sensitive photodetector area;13liquid nitrogen dewar; 14- visual tube. 


\section{INTERNATIONAL JOURNAL OF RESEARCH -GRANTHAALAYAH \\ A knowledge Repository}

Science

ECU structurally of desktop fulfillment. All organs of indication and handle are located on the ECU front panel. In laboratory conditions ECU is installed on desktop, and in field condition it can be installed in a body of auto-laboratory with the help of shock absorbers. The appearances of OMU and ECU "Sipan-A" Spectral Radiometer are shown in Fig.2 (A), (B). Briefly principle of "Sipan-A" operation consists of the following. In OMU the radiation flux from the researched object is going with the help of optical system (see Fig. 1) and is focused on a sensing site of the photo-sensor.

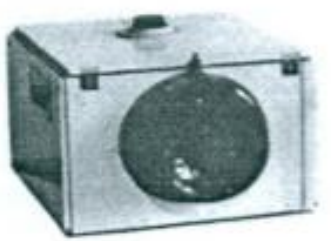

(A)

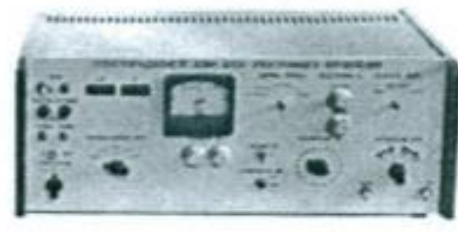

(B)

Figure2: OMU-(A) \& ECU-(B) of "Sipan -A” Spectral Radiometer.

Further, the preamplifier strengthens an electrical signal and transmits to ECU. In ECU the electronic circuits strengthen, demodulated and filtered a signal from an output of the photosensor. In an outcome on the output of ECU, there is a signal, which amplitude is a measure of absolute radiation of the studying object. Knowing the value of the assembled radiation power (with the help of a data preliminary carried out instrument's power calibration), spectral filtering properties of the system and degree of transform of output signal to absolute measurement of the object radiation characteristics. It is necessary to mention, that the knots of photo-sensors includes the InSb and $\mathrm{CdHgTe}$ could photo resistors, for the working in wavelength regions from 2.5 to $5.5 \mu \mathrm{m}$ and from 7.9 to $13.5 \mu \mathrm{m}$ respectively.

The main technical parameters of the "Sipan-A" systems are:

- Entry Objective (Cassegrainian system) Diameter - 108mm

- A focal length - 200mm

- The focused distances - from $5 \mathrm{~m}$ to $\infty$

- Working spectral range -from 2.5 to $13.5 \mu \mathrm{m}$

- Field of View -17ang.min

- Distances, for spectral analysis of hot gas ejection in atmosphere, up to $5000 \mathrm{~m}$

- The volumetric concentration range of the measuring gas pollution in atmosphere from 0.25 LAV (Limited Admit Volume) to $10 \%$ (in volume)

- The IR Radiometric System "Sipan-A" can provide the operative ecological Monitoring of gaseous pollution in the atmosphere.

\section{RESULTS AND DISCUSSION}

The results of distant IR spectral analysis are given of hot gas ejections in the atmosphere from industrial plants. Universal Spectral Radiometer "Sipan-A" has been used for measurements in 


\section{INTERNATIONAL JOURNAL OF RESEARCH -GRANTHAALAYAH \\ A knowledge Repository}

Science

the spectral range 2.5 to $5.5 \mu \mathrm{m}$, at a distance of $3000 \mathrm{~m}$. [2]. In this paper we present the results of our measurements, of $\mathrm{SO}_{2}, \mathrm{~N}_{2} \mathrm{O}$ and hydrocarbon gas content, relative to $\mathrm{CO}$ and $\mathrm{CO}_{2}$ in the 2.5 to $5.5 \mu \mathrm{m}$ waveband.

Smoke and flame ejected by an industrial plant pipe was taken as observation object in our experiments. IR spectral measurements we carried out across a distance of $3000 \mathrm{~m}$, in summer season and in clear weather conditions. Over 20 IR spectrograms have been obtained; the averaged spectrogram is shown in relative units in Fig.3.

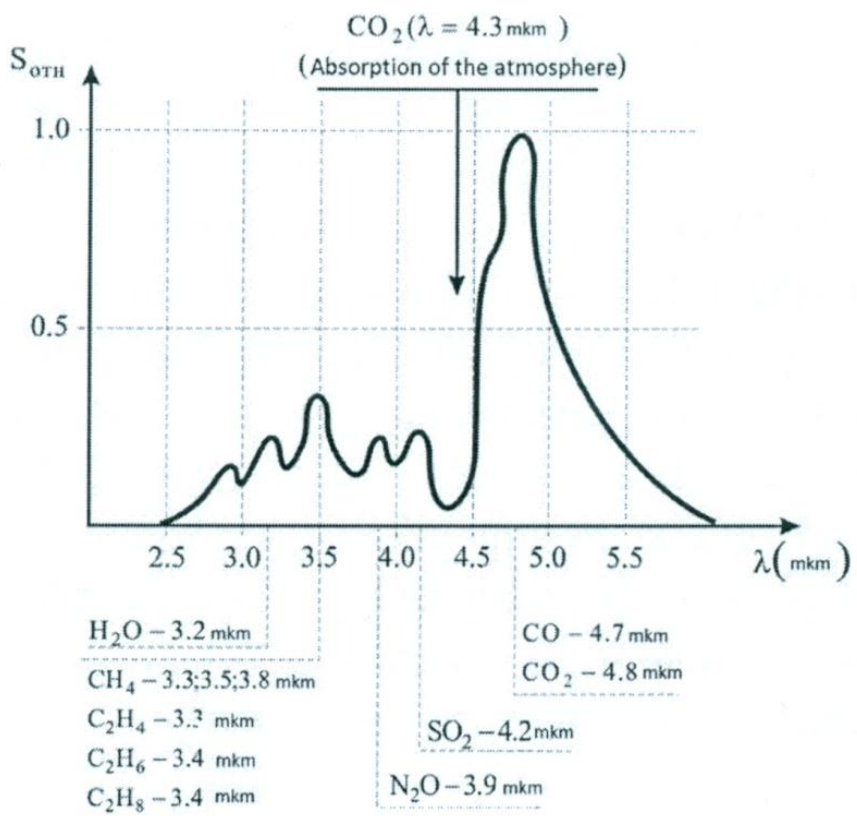

Figure 3: IR spectrogram of hot gas of industrial emissions into the atmosphere.

Note that, due to low spectral resolution $(\approx 3 \%)$, hydrocarbon line group's lines merge into a single band, however their integral intensity may be still compared with that for $\mathrm{CO}$ and $\mathrm{CO}_{2}$, gases, which is important for qualitative analysis in ecology. An intensive $\mathrm{CO}_{2}$, absorption band of the atmosphere is distinctly visible in Fig. 3 at a wavelength $4.3 \mu \mathrm{m}$. [3]. $\mathrm{CO}$ and $\mathrm{CO}_{2}$, gases are known to be the major combustion component, which is reflected in our spectrogram in form of high intensity emission band at $4.7-4.8 \mu \mathrm{m}$ wavelength.

We have selected the 3 - $5 \mu \mathrm{m}$ waveband for measurements because (1) it is one of the main "Transparency windows" in the atmosphere, and (2) because low-concentration gas pollutants, such as hydrocarbons, $\mathrm{N}_{2} 0, \mathrm{~S}_{2}$ etc., possess more or less intensive oscillatory (rotation) spectra in this very range [3]. One may easily identify some groups of these molecules by their emission bands. Most distinctly visible is the hydrocarbon group, with maximum at $3.5 \mu \mathrm{m}$, which is explained by the fact that natural gas was present in the fuel of the plant. 


\section{INTERNATIONAL JOURNAL OF RESEARCH -GRANTHAALAYAH \\ A knowledge Repository}

Science

At a flame temperature above $2000 \mathrm{~K}$, the emission bands of $\mathrm{H}_{2} \mathrm{O}, \mathrm{CO}$ and $\mathrm{CO}_{2}$, gases are broadened to an extent when their spectrum in the range $3-5 \mu \mathrm{m}$ becomes continuous [6]. However, at temperatures below $2000 \mathrm{~K}$ the bands may be resolved, which was indeed observed in our experiment. Comparison of the maximum intensity wavelength in the obtained spectrum with that for the black body radiation, we have found that the effective temperature of gas ejection was in the interval 500 - 600k. Relative content of ejected gases (to $\mathrm{CO}-\mathrm{CO}_{2}$, group) per unit time was evaluated by means of an integral intensity ratio for each gas. One may see that hydrocarbons content is respectively 2 and 3 times higher than $\mathrm{S}_{2}$ and $\mathrm{N}_{2} 0$ content, and on the other hand it is 4 times less then $\mathrm{CO}-\mathrm{CO}_{2}$, group. The obtained results on IR spectrometry of hot gas ejections provide important information about the extent of atmospheric pollution. Our proposed method and used equipment make possible fast determination of content for various hot-gas ejections, by passive spectral measurements in $3-5 \mu \mathrm{m}$ and $8-14 \mu \mathrm{m}$ wavebands.

\section{CONCLUSION}

In IR Radiometer Systems for decrease of overall dimensions and rise of sensitivity, usually, using entry objectives of a type Cassegrainian [4],[5] as is executed in our operation. But the matching developed by us Spectral Radiometer "Sipan-A" with closely existing analog [8] shows at least two clear advantages of the instrument, described in the present paper. With the purpose of the greatest elimination of chromatic aberration in the optical "Sipan-A" system two pairs projections mirror of objectives are applied, and in second, for the extension of instrumentation functionality's on ring disks of a mode of light filters (on region from 3 to to $5 \mu \mathrm{m}$, and from 8 to $14 \mu \mathrm{m})$ are placed half-ring variable cline light filters [8] for spectral measurements of spectrum. Distant IR Spectral analysis of hot gas ejections (both industrial firms, and various vehicles) have huge value, in particular at ecological monitoring of an environment.

\section{REFERENCES}

[1] R.S., Asatryan, et.al. , International Journal of IR and MM Waves, 24, 2003, 1035.

[2] R.S. Asatryan and V.Gevorkyan. In: Proceedings of Ecological and Hydro meteorological Problems in Large Cities and Industrial Zones '2002, Sankt-Petersburg, International Conference, (In Russian) 2002, 95.

[3] V.Zuev, Atmosphere Transparency for Visible and Infrared Beams, Sov. Radio Publ. Moscow (In Russian) 1966.

[4] V. Kozelkin, Fundamentals of infrared Engineering, Mashinostroenie Publ., Moscow (In Russian) 1974.

[5] Yu. Abrahamyan, et.al. YSU Publ. Yerevan (In Russian), 2000.

[6] A. Kadishevich, Simplest methods of Flame Emission Capacity Measurement. Moscow, Oborongiz. (In Russian) 1954.

[7] Dual Cannel Radiometer, US. Patent-3476914. [8] Branch Standard OST3-5683-84 (In Russian), 1984. 